\title{
Reflexiones sobre la ley estatutaria de la Jurisdicción Especial para la Paz desde el Estatuto de Roma*
}

\author{
Reflections on the statutory law of the (Colombian) Special Jurisdiction for \\ Peace, from the Rome Statute
}

\author{
Leidy Marcela Ramírez Hoyos ${ }^{* *}$ \\ Leidy Catalina Duque SalazaR ${ }^{* * *}$
}

Artículo de reflexión como resultado de investigación del Semillero de Derechos Humanos Teyuna Gea del Grupo de Estudios Socio jurídicos de UNICOC -GISU-.

**Abogada. Candidata a Magister en Defensa de los Derechos Humanos y del DIH ante Organismos, Cortes y Tribunales Internacionales. ***Abogada. Docente-Investigadora del Colegio Jurídico de la Institución Universitaria Colegios de Colombia -UNICOC-. Miembro del Grupo de Investigaciones Socio jurídicas UNICOC-GISU. Candidata a Magíster en Defensa de los Derechos Humanos y del DIH ante Organismos, Tribunales y Cortes Internacionales.

DOI: http://dx.doi.org/10.18634/incj.21v.11.915

Fecha de recepción: Marzo de 2019

Fecha de aprobación: julio de 2019

Para citar este artículo / To reference this article Ramírez, L.M., Duque, L.C (2019) Reflexiones sobre la ley estatuitaria de la JEP desde el estatuto de Roma. Inciso 21; 128-146.

\section{Resumen}

El presente artículo de reflexión busca realizar una aproximación al debate sobre la aplicación del Estatuto de Roma en el marco de la implementación del Acuerdo Final para la Terminación del Conflicto y la Construcción de una Paz Estable y Duradera. Por tal motivo, se establece como foco de estudio la Ley Estatutaria de la Administración de Justicia en la Jurisdicción Especial para la Paz a la luz del Estatuto de Roma y la sentencia C-290 de 2012 proferida por la Corte Constitucional, con el fin de identificar los desafíos jurídicos que se trazan bajo el cumplimiento del principio de complementariedad en el contexto social y normativo actual. Para tal efecto, la metodología empleada surge de un proceso cualitativo de tipo documental y jurisprudencial, brindando como resultado la identificación de la jurisprudencia de la Corte Constitucional que resulta orientadora frente al cumplimiento del Estatuto de Roma de cara a la implementación del Acuerdo Final. Por lo tanto, se concluye que la sentencia C-290 de 2002 se torna como un referente útil para resolver las posibles dudas sobre la impunidad en el juzgamiento de máximos responsables de crímenes de guerra o lesa humanidad en relación con el funcionamiento de la Jurisdicción Especial para la Paz.

Palabras clave: Paz, Estatuto, Acuerdo, Derechos. 


\begin{abstract}
This article of reflection seeks to make an approach to the debate on the application of the Rome Statute in the framework of the implementation of the (Colombian) Final Agreement for the End of Conflict and the Construction of a Stable and Lasting Peace. For this reason, it was established as a focus of study, the Statutory Law of the Administration of Justice in the Special Jurisdiction for Peace, in the light of the Rome Statute and judgment C-290 of 2012, issued by the Constitutional Court, in order to Identify the legal challenges that are drawn up in compliance with the principle of complementarity in the current social and regulatory context. For this purpose, the methodology here used starts from a qualitative process of documentary and jurisprudential type, resulting in the identification of the jurisprudence of the Constitutional Court that is guiding in regard with the compliance with the Rome Statute for the implementation of the Final Agreement. Therefore, it is concluded that judgment C-290 of 2002 becomes a useful reference for resolving possible doubts about impunity in the trial of those who have the most responsibility for war crimes, or crimes against humanity, in relation to the functioning of the Special Jurisdiction for peace.
\end{abstract}

Keywords: Peace, Statute, Agreement, Rights.

\title{
INTRODUCCIÓN
}

El proceso de implementación del Acuerdo Final para la Terminación del Conflicto y la Construcción de una Paz Estable y Duradera ha traído consigo la necesidad de una adaptación jurídica que logre armonizarse con los puntos acordados, consistiendo muchos en la garantía de derechos fundamentales en el marco de la protección de los derechos humanos.

En tal sentido, se traza la importancia de expedir una ley estatutaria que logre materializar las disposiciones establecidas en el acuerdo final, motivo por el cual, surgen retos y desafíos en el marco de la aplicación normativa y su armonía con los estándares internacionales e instrumentos internacionales suscritos por Colombia, particularmente, frente al Estatuto de Roma.

Conforme a lo anterior, se desarrolla este artículo a partir de tres líneas centrales; la primera, enfocada en el debate jurisprudencial sobre la aplicación del Estatuto de Roma en el marco de la sentencia C-290; la segunda, hace referencia a la construcción de la Ley Estatutaria y el Estatuto de Roma en la Jurisdicción Especial para la Paz -JEP-; la tercera, dirigida a unas reflexiones finales sobre el análisis del contexto normativo desde la sentencia y el proyecto de ley estatutaria.

Se ha determinado que la década de los cincuenta del siglo XX, deja entrever la agudización del conflicto, tomando como base que Colombia es un país permeado por la violencia a través de la historia, enmarcado en el conflicto armado interno que ha sido motivado en mayor parte por una lucha política, que ha dejado a su paso en el rostro de las víctimas, grandes consecuencias a causa del mismo contexto y de las hostilidades que han repercutido sobre la población civil. "Las cifras reportadas por la Unidad de Víctimas, señalan que hay 8.816.304 víctimas del conflicto armado identificadas hasta el 05 de junio de 2019" (RNI, 2019, p. 1). 
En ese orden, se identifica que una gran cuota del conflicto recae en la población civil que ha sido afectada física y psicológicamente por crímenes de guerra y de lesa humanidad. Varios casos determinantes en derechos humanos en Colombia, han estado tipificados en el crimen de lesa humanidad, como los son: asesinato a líderes de la Unión Patriótica, el caso de Luis Carlos Galán, los desaparecidos del Palacio de Justicia, el caso de Héctor Abad Gómez, las ejecuciones extrajudiciales mal llamadas 'falsos positivos', entre otros. Al ser identificados como crímenes de lesa humanidad se ha adquirido el criterio de imprescriptibilidad que ha permitido la apertura de investigaciones, la identificación de máximos responsables y el juzgamiento de los mismos.

Aunado a esto, el documento parte del reconocimiento a la intensificación del conflicto en las regiones debido a la ausencia de intervención eficaz del Estado, sobre todo en zonas en las que se ha deformado la figura de autoridad y protección de la fuerza pública, y se ha visto mayormente enmarcada en los grupos al margen de la ley, tal y como se ha reflejado en las falencias de las autoridades en la culminación de las investigaciones, más aún cuando los mismos actores del Estado se han encontrado involucrados en grandes violaciones de Derechos Humanos e infracciones al Derecho Internacional Humanitario; un ejemplo corresponde a las ejecuciones extrajudiciales, que surgen a partir de una estrategia diseñada para ofrecer resultados operativos por parte de miembros de la Fuerzas Pública, causando la desaparición y muerte de jóvenes humildes que nunca fueron partícipes de las hostilidades ni formaron parte de grupos armados.

Bajo esta línea argumental, se plantea la importancia de desarrollar un análisis sobre la situación jurídica que enmarca el proceso de transición que aborda el país a partir de la implementación del acuerdo final, así como la importancia de revisar el alcance de los instrumentos internacionales como el Estatuto de Roma en relación con la Jurisdicción Especial para la Paz. Con base en estos presupuestos, se postula el debate ante la comunidad académica, teniendo en cuenta los múltiples desafíos que prevalecen frente a las dinámicas políticas, sociales y jurídicas actuales.

\section{Materiales y métodos}

Esta investigación es de orden cualitativo, con enfoque socio-jurídico, de tipo documental y jurisprudencial. Por tanto, emplea el análisis jurisprudencial como forma de determinar los estudios realizados por la Corte Constitucional sobre el Estatuto de Roma. Igualmente, es de carácter descriptivo y analítico, tomando como base la revisión de las consideraciones existentes sobre la implementación de la Ley Estatutaria de la JEP.

\section{Debate jurisprudencial sobre la aplicación del Estatuto de Roma a la luz de la sentencia C-290 de 2012}

La sentencia consiste en una demanda de inconstitucionalidad interpuesta por el ciudadano David Delgado Vitery contra el artículo 1 de la Ley 1426 de 2010 "Por la cual se modifica la Ley 599 de 2000, relativa a las conductas punibles que atentan contra los bienes jurídicamente protegidos de los defensores de derechos humanos y periodistas", por considerar que viola los 
artículos 5, 6 y 29 del Estatuto de Roma de la Corte Penal Internacional, al igual que los artículos 13 y 93 superiores.

Si bien la Corte Constitucional cuenta con una lista importante de pronunciamientos que se han referido al Estatuto de Roma entendido como instrumento de derecho internacional y su relación con el ordenamiento jurídico interno, por medio de las sentencias C-578/02, C-928/05, T-821/07, C-801/09, y el auto A009/15, la sentencia en mención para este acápite (C-290 de 2012), presenta criterios importantes que pueden ser tenidos en cuenta para el análisis de la Ley Estatutaria de la Administración de Justicia en la Jurisdicción Especial para la Paz, a la luz del Estatuto de Roma.

Así las cosas, según la sentencia el demandante argumentó que el artículo en controversia establece un: "Término de prescripción de 20 a 30 años para las conductas punibles de genocidio, desaparición forzada, tortura y homicidio de miembro de una organización sindical legalmente reconocida, homicidio de defensor derechos humanos, homicidio de periodista y desplazamiento forzado, resultando contrario a los artículos 5, 6 y 29 del Estatuto de Roma (sentencia C-290, 2012). De igual modo, indica que los instrumentos internacionales que han sido objeto de ratificación y aprobación por parte del Estado, cuentan con poder y fuerza vinculante en el sistema normativo, dando como resultado su prevalencia en el bloque de constitucionalidad, la postulación de ser norma superior y la disposición de la derogación de normas que resulten contrarias al contenido sustancial de lo aprobado en el contenido del tratado.

Bajo este entendido, mientras el artículo primero de la Ley 1426 de 2010 "Por la cual se modifica la Ley 599 de 2000, relativa a las conductas punibles que atentan contra los bienes jurídicamente protegidos de los defensores de derechos humanos y periodistas", impone un término de prescripción de la acción penal para los delitos señalados, el artículo 29 del Estatuto de Roma sienta una regla en sentido categórico diciendo: "Los crímenes de competencia de la Corte no prescribirán" (Congreso de la República, 2010). Por lo tanto, la parte demandante concluye que existe una vulneración, pues los derechos que corresponden a las víctimas reconocidos universalmente como el acceso a la justicia, a la verdad y a la reparación, se ven afectados ante la configuración de un término de prescripción de la acción penal.

Por su parte, la Corte Constitucional establece un hilo conductor en el análisis del argumento presentado frente a la norma demandada, logrando unas conclusiones importantes al respecto, estructurándolos así: i) Pronunciamientos anteriores a la entrada en vigor del Estatuto de Roma para Colombia. ii) El control de constitucionalidad sobre el Estatuto de Roma y su ley aprobatoria. iii) Pronunciamientos de la corte con posterioridad a la sentencia C-578/02.

\section{Pronunciamientos anteriores a la entrada en vigor del Estatuto de Roma para Colombia}

Conforme al primer punto, la Corte plasma la importancia de hablar sobre sus pronunciamientos anteriores a la entrada en vigor del Estatuto de Roma para Colombia, indicando que pese a la ratificación del instrumento el 6 de enero de 2001, y su incorporación el 6 de noviembre del mismo año salvo los delitos relacionados con los crímenes de guerra que cobraron vigencia en el año 2008, para tales fechas la Corte Constitucional ya había hecho referencia a la creación y puesta en marcha de la Corte Penal Internacional. Si bien el Estatuto de Roma no era empleado 
como un instrumento incluido en el Bloque de Constitucionalidad, se tenía en cuenta como base de interpretación que permitiera el análisis de un referente aplicable en la legislación interna conforme a algunos principios y prácticas surgidas de este instrumento.

De este modo, hace mención de la sentencia C-621/01 que presenta consideraciones sobre la aplicación territorial de la ley penal, expresando ejemplos internacionales en los que se han utilizado cortes penales internacionales para el juzgamiento, tal y como sucedió con el tribunal internacional para el juzgamiento del delito del genocidio, o la Corte Penal Internacional como resultado del Estatuto de Roma, que pese a no estar en vigor en el contexto temporal, hacía fiel alusión al objeto de explicación frente a los criterios territoriales de la ley penal.

A su vez, la sentencia de unificación SU-1184/01, trae a colación entre los temas estudiados por la Corte Constitucional, criterios sobre el juzgamiento de miembros de la fuerza pública por la comisión de crímenes internacionales, implicando la necesidad de remitirse al artículo 28 del Estatuto de Roma para resaltar la posición garante que ha mantenido el derecho penal internacional (Corte Constitucional, 2001), puesto que la misma enunciación de la responsabilidad de los jefes y otros superiores, plasmada en este artículo, responde a la consecución normativa positiva del derecho penal consuetudinario que se desarrolló en la jurisprudencia de los tribunales penales internacionales, desde Núremberg hasta los ad-hoc para la ex Yugoslavia y Ruanda.

Por el contrario, la Corte Constitucional profirió la sentencia C-181 de 2002, en la que sí se realizó control de constitucionalidad respecto al artículo 28 del Estatuto de Roma sobre una norma legal, donde se examinó la validez de la consagración de la falta disciplinaria de comisión de genocidio, prevista en el literal a) del artículo 25.5 de la Ley 200 de 1995. En dicha ocasión, el juez constitucional consideró lo siguiente, siendo parte esencial de las consideraciones la siguiente conclusión:

(...) Es posible admitir que, en casos excepcionalísimos, la comisión del genocidio podría darse a título de imprudencia, pero únicamente en relación con jefes y superiores encargados de proveer seguridad a un determinado grupo social, tal como lo dispone el artículo 28 del Estatuto de la Corte Penal Internacional (Corte Constitucional, 2002, p. 48).

Cabe resaltar entonces que para esta jurisprudencia, la Corte acude de manera muy cuidadosa al Estatuto de Roma, brindándole un salto cualitativo de ser un criterio importante de interpretación entre los instrumentos internacionales, a la identificación de un articulado exclusivo para ser tenido en cuenta en el bloque de constitucionalidad.

Finalmente, la sentencia C-228 de 2002, habla sobre el Estatuto de Roma para argumentar lo aspectos definidos sobre los derechos de las víctimas y su debida protección en los procesos penales respecto a la constitución del proceso civil planteada en la demanda frente al proceso penal. En la misma, la corte recalca que hace referencia al Estatuto de Roma aún cuando todavía no se encuentra en vigor y sin que ello signifique un pronunciamiento sobre su constitucionalidad.

\section{El control de constitucionalidad sobre el Estatuto de Roma y SU LEY APRobatoria}

La Corte Constitucional realizó el control de constitucionalidad para la revisión del Estatuto de 
Roma y su ley aprobatoria, implicando desarrollar la estrategia de insertar un nuevo artículo en la Constitución que permitiera superar todos los problemas constitucionales relacionados con este instrumento internacional, y evitara la tendencia de incluir excepciones a cada uno de sus artículos.

Los problemas constitucionales sobre los cuales se consideró necesario realizar precisiones, por considerarse contrarias a la tradición jurídica colombiana fueron: La posibilidad de imponer la reclusión perpetua como pena, y la imprescriptibilidad de las acciones derivadas de la comisión de hechos punibles sancionados en el articulado del Estatuto de Roma.

En ese sentido, atendiendo a la estrategia para superar los problemas constitucionales en relación con la Corte Penal Internacional, se profiere el Acto Legislativo 02 de 2001, que permite a la Corte Constitucional concluir que su contenido no deroga ni sustituye a la Constitución, sino que se incorpora a ella bajo la técnica de la adición de un artículo constitucional, el 93 de la Carta. Esta adición empieza diciendo que el Estado colombiano puede reconocer la jurisdicción de la Corte Penal Internacional, y, consecuentemente, ratificar este tratado de conformidad con el procedimiento establecido por la Constitución, dando a entender que el propósito final del acto legislativo no fue incorporar directamente el tratado a la Constitución ni hacer imperativa su ratificación.

A su vez, el acto legislativo establece que las normas del Estatuto surten efectos dentro del ámbito de la competencia de la Corte Penal Internacional y las disposiciones en él contenidas no remplazan ni modifican las leyes nacionales de tal manera que a quien delinca en el territorio nacional se le aplicará el ordenamiento jurídico interno y las autoridades judiciales competentes al efecto son las que integran la administración de justicia colombiana. De este modo, la Corte Constitucional aclara que cuando la CPI ejerza su competencia complementaria en un caso colombiano, podrá aplicar en su integridad el texto del Estatuto de Roma.

Por último, se hace especial énfasis en la disposición que sobrepone al Estatuto de Roma como un instrumento que no modifica el derecho interno aplicado por las autoridades judiciales colombianas en ejercicio de las competencias que son propias dentro de la jurisdicción interna, debido a la naturaleza misma del tratado y el principio de complementariedad.

En materia de imprescriptibilidad de los crímenes de competencia de la CPI, se está en presencia de un "tratamiento diferente", que de conformidad con el Acto Legislativo 02 de 2001, se realiza una regulación aplicable exclusivamente en el ámbito de competencia de la CPI, sin que modifique o cambie la legislación interna. En esa medida: "Tal tratamiento especial sólo será aplicable por la Corte Penal Internacional cuando ejerza su competencia complementaria para investigar y juzgar cualquiera de los crímenes previstos en el Estatuto, así la acción penal o la sanción penal para los mismos haya prescrito según las normas jurídicas nacionales" (Sentencia C-290, 2012, p. 26).

\section{Pronunciamientos de la corte con posterioridad a la sentencia C-578/02}

Frente a los posteriores pronunciamientos, uno de los aspectos más relevantes sobre los cuales ha conciliado la Corte, responden a la concreción clara las disposiciones del Estatuto de Roma 
que forman parte del bloque de constitucionalidad, siendo de esta manera los siguientes:

(...) El Preámbulo (C-928 de 2005); el artículo 6, referido al crimen de genocidio (C- 488 de 2009); artículo 7, relacionado con los crímenes de lesa humanidad (C- 1076 de 2002); artículo 8, mediante el cual se tipifican los crímenes de guerra (C- 291 de 2007, C-172 de 2004 y C- 240 de 2009); el artículo 20, referido a la relativización del principio de la cosa juzgada (C- 004 de 2003 y C- 871 de 2003), al igual que los artículos 19.3, 65.4, 68, 75 y 82.4, concernientes a los derechos de las víctimas (C- 936 de 2010). En consecuencia, la Corte ha preferido determinar, caso por caso, qué artículos del Estatuto de Roma, y para qué efectos, hacen parte del bloque de constitucionalidad (Sentencia C-290, 2012, p. 31).

Con base en lo anterior, se identifica una evolución descubierta por la Corte Constitucional, consistente en la determinación de lo que se entenderá como parte del bloque de constitucionalidad respecto al Estatuto de Roma, determinando de este modo, la sustracción de los artículos que estrictamente se relacionan con la protección de derechos humanos, y conservando en articulado que por su parte, sólo se tomará su aplicación integral a partir de la definición de competencia con base en el principio de complementariedad.

De esta manera, se resuelve uno de los desafíos más grandes que para antes del año 2002, persistían en relación con la vinculación del Estatuto de Roma a la norma superior y la posibilidad de invocarlo como parte del artículo 93 de la Constitución y, por ende, acudir ante la Corte Constitucional mediante la acción pública de inconstitucionalidad.

\section{El Estatuto de Roma en Colombia de cara a la sentencia C-290 de 2012}

La sentencia enfatiza en la obligación que tiene Colombia, como estado social de derecho, de investigar dentro de un determinado tiempo la presunta comisión de un hecho punible para velar por la dignidad de la persona y el respeto efectivo de los derechos humanos.

Por su parte, el artículo 28 de la Constitución Política de Colombia dispone: “(...) En ningún caso podrá haber detención, prisión ni arresto por deudas, ni penas y medidas de seguridad imprescriptibles" (1991). Sobre este supuesto, se puede definir que en virtud de esta disposición constitucional fue necesario discutir el criterio de imprescriptibilidad para la adopción del Estatuto de Roma, pues en efecto, interferiría con la tradición jurídica colombiana relacionada con la imposición de penas. En ese orden, resulta necesario revisar el artículo 83 del Código Penal que es modificado por la Ley 1719 de 2014, pues expresa:

El término de prescripción para las conductas punibles de desaparición forzada, tortura, homicidio de miembro de una organización sindical, homicidio de defensor de Derechos Humanos, homicidio de periodista y desplazamiento forzado será de treinta (30) años. En las conductas punibles de ejecución permanente el término de prescripción comenzará a correr desde la perpetración del último acto. La acción penal para los delitos de genocidio, lesa humanidad y crímenes de guerra será imprescriptible (Congreso de la República, 2014, p. 1).

Como es de observarse, la incongruencia persiste en tanto el texto constitucional se refiere a la pena, el Código Penal hace mención a la acción penal, y la Corte Constitucional mediante la sentencia C-290/12 se refiere a ambos sin distinción. En todo caso, se ha interpretado que 
en el ordenamiento jurídico interno colombiano, puede asumirse la imprescriptibilidad de la acción penal para delitos de genocidio, lesa humanidad y crímenes de guerra, sólo a partir del año 2014 que es cuando logra normativizarse esta disposición. Asimismo, es un criterio realmente limitado en la aplicación del derecho, pues el único delito tipificado hasta el momento es el genocidio, continuando el reto de amoldar la normatividad nacional para la tipificación del crimen de lesa humanidad y el crimen de guerra.

Se considera entonces, que la Corte Constitucional hace una valoración limitada del carácter de imprescriptibilidad en el marco de los crímenes internacionales, pues pervive una incongruencia en el criterio que establece la Corte Constitucional, lo contenido en la Constitución Política de Colombia y lo dispuesto en el Código Penal Colombiano. Lo anterior, teniendo en cuenta que, si bien la Corte Constitucional desarrolla una línea argumental enfocada a reconocer la imprescriptibilidad de los crímenes internacionales ante la Corte Penal Internacional, pero no en la misma medida sobre el derecho interno, lo cierto es que la Corporación no realiza una distinción entre la prescripción de la acción penal y la prescripción de la pena, motivo por el cual, en términos de aplicabilidad, la interpretación dada por la Corte alrededor de la acción penal y la pena resulta inconclusa.

\section{Resultados}

Según cifras de un estudio revelado por el programa Somos Defensores, existe un nivel de impunidad del 87 \% en los 458 crímenes perpetrados contra defensores de derechos humanos entre 2009 y 2016 . El $62 \%$ de los casos se encuentra en etapa de indagación, y en un 22\% la fiscalía no registra información de avance, motivo por el cual es difícil develar una sistematicidad de los hechos (Osorio, 2017). Esta observación ha transcurrido por más de 8 años, lo que demuestra la inefectividad del Estado colombiano para investigar estos hechos, mostrando un horizonte desalentador pues aún quedan 22 años para una investigación "efectiva".

Un ejemplo que refleja este contexto, es el asesinato de los investigadores del Centro de Investigación y Educación Popular-CINEP- Mario Calderón, Elsa Alvarado y Carlos Alvarado, quienes llevan más de 20 años de impunidad (Contreras, 2017), situación que determina la responsabilidad que aún tiene el Estado con su familia y con la sociedad para el esclarecimiento de la verdad. De este modo, se deja en entre dicho que aumentar el tiempo de imprescriptibilidad por 10 años más haya sido justo con los familiares que tienen derecho a saber la verdad, pero con celeridad y no de la forma inoperante e incompetente que ha desarrollado el Estado o sus agentes.

Esta lectura se relaciona con la situación actual de los líderes sociales, pues según la Fiscalía General de la Nación, 178 han sido asesinados entre 2016 y 2018 (Fiscalía General de la Nación, 2018), motivo por el cual se demarca el lugar del derecho penal internacional en términos del seguimiento a los casos que sobrepasan el contexto de conflicto armado y prevalecen en la escala del conflicto social y político.

Actualmente, una de las principales falencias en Colombia es la ausencia de políticas públicas que establezcan protocolos adecuados para la investigación de homicidios contra defensores de 
derechos humanos, en tanto se evidencia un desinterés y silencio estatal que puede corroborarse en las cifras de sus muertes que difieren entre los reportes de las entidades estatales.

\section{Proyecto de ley estatutaria de administración de la Jurisdicción Especial para la Paz (JeP)}

Colombia se encuentra en un estado de transición hacia a la paz luego de la firma del "Acuerdo final para la terminación del conflicto y la construcción de una paz estable y duradera" el pasado 24 de agosto del año 2016, en la Habana, Cuba por integrantes de las Fuerzas Armadas Revolucionarias de Colombia Ejército del Pueblo FARC-EP y el Gobierno Nacional. Debe reconocerse que con los acuerdos se han disminuido las muertes de civiles y combatientes, contexto rescatable cuando una sola pérdida de una vida humana tiene un valor incalculable.

Atendiendo a todo este proceso de cambio y a la intención por parte del Estado de la búsqueda de justicia, verdad, reparación y garantías de no repetición, implica unos procesos de implementación que puedan garantizar el cumplimiento de los acuerdos, entre ellos, la adecuación o creación de modelos legislativos como el Proyecto de Ley Estatutaria de Administración de la JEP (Ley estatutaria 08 de 2017-Senado y 016 de 2017-Cámara). Esta herramienta pretende definir la situación jurídica de los actores del conflicto que podrán acogerse a la Justicia Especial para la Paz, en tanto sean integrantes de las FARC-EP, miembros de la fuerza pública y terceros civiles.

El proyecto de ley da desarrollo al Sistema Integral de Verdad, Justicia y No Repetición, que está compuesto por los siguientes mecanismos y medidas: la Comisión para el Esclarecimiento de la Verdad, la Convivencia y la No Repetición; la Unidad para la Búsqueda de Personas dadas por Desaparecidas en el contexto y en razón del conflicto armado; la Jurisdicción Especial para la Paz; y las medidas de reparación integral para la construcción de paz y las garantías de no repetición.

En el punto que concierne a este escrito, se hará énfasis en la Jurisdicción Especial para la Paz, que a su vez se compone de una Sala de Revisión de Verdad, Sala de amnistía o indultos, Sala de Definición de Situaciones Jurídicas, Unidad de Investigación y Acusación, Tribunal para la Paz. Finalmente, dentro de los órganos de gobierno y administración se encuentra la Secretaría Ejecutiva.

El proceso de aprobación del proyecto de ley ha sido objeto de observación por parte de las organizaciones sociales, civiles y políticas, en relación con el funcionamiento de la JEP en el marco de justicia diseñado para los actores que lograrían entrar en el proceso. Así pues, este modelo de jurisdicción ha sido fuertemente cuestionada por algunos actores que postulan que los crímenes más graves quedarán en la impunidad, como lo son masacres y ejecuciones extrajudiciales.

De igual forma, las críticas no solo han tenido vida en las dinámicas internas nacionales, sino también a nivel internacional y quedó demostrado en un escrito de Amicus Curiae, realizado por la Fiscal de La Corte Penal Internacional, Fatou Bensouda, en donde manifestó su preocupación por la definición e interpretación de la Responsabilidad del mando en esta jurisdicción, pues se concibe alejada de los estándares internacionales como lo es el Estatuto de Roma. 


\section{AnÁlisis SOBRe La RESPONSABILIDAd del maNdo}

Argumentaba la fiscal que un tribunal que aplique el artículo transitorio 24 del Acto Legislativo 01 del 4 de abril de 2017, tal como está formulado, podría verse impotente para hacer cumplir el Derecho Internacional Consuetudinario solo sobre los jefes militares con autoridad de facto pero no de jure, en vista de que solamente se puede aceptar como prueba el grado de mando exigido por un nombramiento formal. Esto significaría que las personas con capacidad material de prevenir o de castigar los crímenes de los subordinados, que hubiesen omitido hacerlo a sabiendas, podrían quedar impunes. Adicionalmente, este fenómeno socavaría de manera importante la aplicación del principio de la responsabilidad del mando y pondría en duda si esos procesos estarían viciados por la incapacidad o la falta de disposición de llevarlos realmente a cabo (Bensouda, 2017). Del mismo modo, el escrito de Amicus Curiae de la Fiscal de la Corte Penal Internacional sobre la Jurisdicción Especial para la Paz ante la Corte Constitucional, expresa:

La definición de responsabilidad del mando incluida en el Acto Legislativo 01 se aparta del derecho internacional consuetudinario y, en consecuencia, podría frustrar los esfuerzos de Colombia por cumplir sus obligaciones de investigar y juzgar los crímenes internacionales. La definición parecería revivir consideraciones de jure para establecer si un superior podría ser considerado responsable por no haber prevenido o castigado a sus subordinados, y podría dar lugar a la sustracción de la responsabilidad penal de individuos que tienen la mayor responsabilidad por actos atroces, debido a la ambigüedad para determinar si una persona ha tenido una "participación activa o determinante (Bensouda, 2017, p. 4).

No obstante, se establece que para evitar esta impunidad Colombia, de acuerdo con el artículo 93 constitucional, está en la obligación de adecuar su normatividad a nivel interno de tal modo que si por su inoperancia u omisión no es posible endilgar una responsabilidad penal individual, entonces la Corte Penal Internacional pueda aplicar su Estatuto de Roma y su imprescriptibilidad en crímenes graves (CPI, 2002). Por su parte, varias organizaciones que han seguido de cerca el proceso de implementación del acuerdo final, corroboraron en un documento las críticas realizadas por la fiscal de la CPI, titulándolo Comentarios sobre el Proyecto de Ley Estatutaria de Administración de la Jurisdicción Especial Para La Paz (JEP), mencionando en relación con el Estatuto de Roma lo siguiente:

El pasado 18 de octubre, la Fiscal de la Corte Penal Internacional, Fatou Bensouda, presentó un amicus curiae ante la Corte Constitucional sobre el AL 1/2017, en el que llamó la atención respecto a la regulación de la responsabilidad de terceros contenida en el artículo 16 transitorio. En concreto, la Fiscal resaltó la ambigüedad del requisito de la "participación activa o determinante", que se exige para que un tercero pueda ser investigado y sancionado por la JEP. El llamado de la Fiscal genera preocupación por la forma en que el artículo 62 del PLE 08-16/2017 reglamenta el alcance de la competencia de la JEP respecto de la responsabilidad de terceros (Dejusticia, 2017, p. 21).

Como está dispuesto, las críticas se encaminan a establecer que la connotación de participación activa o determinante se encuentra escasamente definida a partir de la intención directa, definición que en el derecho penal colombiano no se encuentra tipificado, motivo por el cual se 
agudiza la ambigüedad de su alcance y comprensión. En esa medida, menciona la fiscal que si el concepto se interpretara como el de dolo directo, la actual redacción permitiría incluir casos en los cuales el tercero, sin necesariamente desear la comisión de los crímenes por parte del grupo armado, pudo prever que con seguridad estos se cometerían con su participación, por ende, esta interpretación estaría en conformidad con el estándar subjetivo aplicado por los tribunales penales internacionales ad hoc, criterio que sería sensato para el trabajo de la JEP (Dejusticia, 2017).

Sin embargo, debido a que la interpretación de intención directa es realmente amplia, en cuanto también podría ser el hecho de prestar el aporte con el propósito de facilitar los crímenes, se entiende que este criterio limitaría indebidamente la responsabilidad de aquellos terceros que participaron en los crímenes de los grupos armados por motivos económicos, solamente con conocimiento y no con el deseo de que sus aportes facilitaran la comisión de graves crímenes. Es decir, no habría una aplicabilidad concreta a la luz de esta expresión que no permite materializar los elementos de la responsabilidad de terceros en el Tribunal para la Paz.

Hay que tener en cuenta que la competencia de la CPI es de carácter subsidiario, es decir, que esta solo actuará como corte de último recurso en situaciones donde la justicia nacional sea ineficaz para normalizar la situación, o donde se demuestre un grado tal de poder de los enjuiciados que la justicia aún actuando, solo busque exonerar a los responsables de sus penas (Franco, 2017). Las discusiones sobre complementariedad de la Corte Penal Internacional (CPI) en escenarios de transición que involucran a autores de graves crímenes internacionales (core crimes), parten fundamentalmente del análisis entorno a la realización de una dimensión especial del deber jurídico de persecución penal (Ambos, 2010) entendiendo esto la JEP, mientras mantenga respeto de las obligaciones internacionales del Estado (Franco, 2017).

En consecuencia, si en la Jurisdicción Especial de Paz hubiera impunidad respecto de crímenes de guerra, cometidos después de 2009, o crímenes de lesa humanidad y genocidio posteriores al año 2002, la Corte Penal Internacional podría juzgar a jefes militares, guerrilleros y superiores civiles. Si los llamados falsos positivos, revelados a finales de 2006, se consideran delitos de lesa humanidad, como lo ha hecho el Consejo de Estado, y no tuvieran sanciones efectivas ni se sometieran a la Jurisdicción Especial de Paz, igualmente podrían ser sancionados por la Corte Penal Internacional (Charry, 2017). Fundación Ideas para la Paz, la Comisión Colombiana de Juristas y la Universidad del Rosario, realizaron algunos comentarios al Proyecto de Ley Estatutaria de Administración de la JEP, así:

- No es claro si las normas de procedimiento elaboradas por los magistrados de la JEP deberían ser aprobadas por el Congreso mediante una ley.

- Se realiza distinción injustificada entre los presuntos responsables, que deben responder ante este sistema de justicia.

- Se circunscribe la facultad de aplicar los principios de selectividad en la Sala de Definición de Situaciones Jurídicas, cuando también podrían hacerlo las otras salas.

- El Ministerio de Defensa Nacional, como órgano de la Rama Ejecutiva, no tiene la facultad 
para evaluar qué conductas fueron cometidas en el marco del conflicto armado, toda vez que es de origen constitucional y asignado a un órgano jurisdiccional como la JEP.

- No hay articulación en las funciones de los centros de reclusión para el monitoreo y vigilancia de los miembros de la Fuerza Pública.

- Los mandos de la guerrilla solamente serían responsables por los crímenes de sus subalternos si aquellos tenían un conocimiento cierto y efectivo de los hechos. Siendo contraria al estándar del DIH y el DPI que incluye también el conocimiento inferido. (FIP, Universidad del Rosario, Comisión Colombiana de Juristas, 2017, p. 12).

José Miguel Vivanco, Director Ejecutivo para las Américas de Human Rights Watch (HRW), calificó de "plagada de defectos" la iniciativa que busca crear el marco regulatorio de la justicia que actuará para juzgar a las Farc, militares y civiles por los delitos cometidos en el marco del conflicto armado. Además, manifestó serias objeciones al hecho de que: "El componente de justicia del acuerdo de paz pueda permitir que responsables de crímenes de guerra no reciban un castigo genuino por los delitos graves de los que son responsables", por ejemplo, la justicia ordinaria deberá cancelar todos los procesos que lleve en contra de los desmovilizados que hayan cometido delitos en el desarrollo de la guerra (Vivanco, 2017, p. 17).

A continuación se traen a colación algunos casos de acusados por el Tribunal Penal Internacional para la ex Yugoslavia, que refleja la responsabilidad del mando, así:

- Zlatko Aleksovski, Bosniocroata, Comandante de prisión, Condenado a 7 años de prisión por Tratamiento ilegal de los detenidos en la zona del valle del Lašva, en Bosnia y Herzegovina.

- Milan Babić Serbocroata, primer Ministro de la República Serbia de Krajina, Condenado a 13 años de prisión el 18 de julio de 2005, Participación en la limpieza étnica en Croacia

- HaradinBala, Albanokosovar, guardia del campo de prisioneros de Lapušnik del Ejército de Liberación de Kosovo, Condenado a 13 años de prisión en 2007, Participación directa en los asesinatos de serbios en las montañas Bersisha.

- Ljubiša Beara, Serbobosnio, coronel de la Policía Militar, Condenado a cadena perpetua., por genocidio, asesinato, persecución y deportación forzosa durante la masacre de Srebrenica y la toma de Žepa.

- Vidoje Blagojević, Serbobosnio, oficial del Ejército de la República Srpska (VRS), Condenado a 15 años de prisión en 2007, Participación en la masacre de Srebrenica. (Tribunal Penal Internacional para la ex Yugoslavia, 2005, p. 2)

Esto es solo una muestra ejemplarizante de lo que podría aplicarse en Colombia en caso de permitir la competencia e intervención de la Corte Penal Internacional para establecer la responsabilidad individual de altos mandos del Estado, que aún hoy están en la impunidad. Otros ejemplos de la aplicación de la responsabilidad del mando es la de los casos juzgados por el Tribunal Penal Internacional para Rwanda ("TPIR"), como el caso de Akayesu que constituye un hito mundial al ser considerado la primera condena internacional por genocidio y la primera 
en reconocer la violencia sexual como actos constitutivos de genocidio. Declaró a un acusado culpable de violación por no haber impedido ni detenido una violación en su calidad de oficial, y no por haberla cometido personalmente. Así pues, Jean Paul Akayesu, antiguo alcalde de la ciudad ruandesa de Taba, fue sentenciado a prisión de por vida 1998, por genocidio, incitación directa y pública a cometer genocidio y crímenes de lesa humanidad (Tribunal Penal Internacional para Ruanda, 1994).

\section{ACERCA de LA PARTICIPACIÓN DE TERCEROS EN EL MARCO de LA COMPETENCIA de LA JEP}

Otro punto crítico sobre la Ley Estatutaria de la JEP, tiene que ver con la participación de terceros y su comparecencia en la jurisdicción especial. Tomando como base lo anterior, se tiene que el "Acuerdo Final para la Terminación del Conflicto y la Construcción de una Paz Estable y Duradera", entre muchas de las disposiciones relacionadas con la construcción de la JEP, estableció parámetros sobre su competencia hacia terceros vinculados al conflicto, indicando que el funcionamiento del componente de justicia del SIVJRNR es inescindible y se aplicará de manera simultánea e integral a todos los que participaron directa e indirectamente en el conflicto armado, articulándolo además con el siguiente criterio:

También serán de competencia de la Jurisdicción Especial para la Paz las conductas de financiación o colaboración con los grupos paramilitares, o con cualquier actor del conflicto, que no sean resultado de coacciones, respecto de aquellas personas que tuvieron una participación activa o determinante en la comisión de los crímenes competencia de ésta jurisdicción, según lo establecido en el numeral 40 , salvo que previamente hubieren sido condenadas por la justicia por esas mismas conductas. (Alto Comisionado parala Paz, 2016, p. 149).

Con base en este precedente, la introducción del Acuerdo Final a la normatividad colombiana por medio del Acto Legislativo 01 de 2017, "por medio del cual se crea un título de disposiciones transitorias de la Constitución para la terminación del conflicto armado y la construcción de una paz estable y duradera y se dictan otras disposiciones", implicó que se destinara un artículo referente a la competencia sobre terceros incluyendo en su desarrollo el artículo 16 Transitorio de la siguiente manera:

Artículo transitorio $16^{\circ}$. Competencia sobre terceros. Las personas que sin formar parte de las organizaciones o grupos armados, hubieren contribuido de manera directa o indirecta a la comisión de delitos en el marco del conflicto, podrán acogerse a la JEP y recibir el tratamiento especial que las normas determinen, siempre que cumplan con las condiciones establecidas de contribución a la verdad, reparación y no repetición. Lo anterior, sin perjuicio de las competencias de la Sala de Reconocimiento de Verdad y Responsabilidad y de la Sección de Revisión del Tribunal para la Paz, respecto de la comparecencia de aquellos terceros que hubieran tenido una participación activa o determinante en la comisión de los siguientes delitos: el genocidio, delitos de lesa humanidad, los graves crímenes de guerra -esto es, toda infracción del Derecho Internacional Humanitario cometida de forma sistemática-, la toma de rehenes u otra privación grave de la libertad, la tortura, las ejecuciones extrajudiciales, la desaparición forzada, el acceso carnal violento y otras formas de violencia sexual, la sustracción de menores, el desplazamiento forzado, además del reclutamiento de menores, todo ello conforme a lo establecido en el Estatuto 
de Roma. Se entiende por participación determinante para estos efectos aquella acción eficaz y decisiva en la realización de los delitos enunciados. En el ejercicio de esas competencias, las mencionadas Sala y Sección no podrán fundamentar su solicitud y decisión exclusivamente en los informes recibidos por la JEP, sino que deberán corroborarlos a través de otros medios de pruebas (Acto Legislativo 01, 2017, p. 1).

Sobre este artículo se puede vislumbrar la intención de la JEP por incluir a todos los actores del conflicto que directa o indirectamente tuvieron una participación, por ende, serían destinatarios del sistema de justicia diseñado para la superación del conflicto. En todo caso, al tratarse de un Acto Legislativo, fue necesario surtir el control automático, único y posterior de la Corte Constitucional, para establecer si el Acto Legislativo 01 de 2017 cumple con los parámetros procedimentales previstos en la Constitución Política.

Entre los diversos puntos analizados por la Corte, se encontró el del artículo 16 transitorio respecto a la competencia sobre terceros, donde la corporación encontró varios puntos por discutir; en primer lugar, la posible anulación de la garantía del juez natural en tanto le correspondía a la JEP hacer comparecer ante ella a aquellos terceros que hubieren tenido una participación activa o determinante en la comisión de los delitos previstos en el inciso $2^{\circ}$ del artículo 16 del Acto Legislativo 01 de 2017; en segundo lugar, el desconocimiento de las garantías orgánicas, procesales y sustantivas de un juicio justo e imparcial ante la competencia obligatoria de la JEP respecto de los terceros civiles.

Es así como la corte concluye que la creación del sistema de justicia es admisible solo para los combatientes, determinando que los demás actores (terceros vinculados al conflicto), no se deben someter de manera forzosa. Sobre el particular los no combatientes como los terceros civiles, no serán sometidos de forma imperativa a la JEP, pues en argumentos de la Corte Constitucional, se produciría un cambio orgánico en la instancia jurisdiccional encargada de la investigación, juzgamiento y sanción de los delitos cometidos en el marco del conflicto armado, además, de una transformación sustantiva en el modelo de justicia al que estos deberían acceder.

De este modo, la corte aduciendo al carácter voluntario y no obligatorio de la comparecencia de terceros a la JEP, reitera el sistema de condicionalidades establecido de manera general en el Acto Legislativo 01 de 2017, indicando que el régimen penal especial al que puedan tener acceso según lo determine el legislador, depende de la oportunidad y de la calidad de su aporte de verdad, así como de su contribución a la verdad, a la reparación de las víctimas y a la no repetición. Por lo tanto, resalta que los terceros civiles que pretendan acceder a la JEP y a los tratamientos especiales comprendidos por esta, no escapan a la lógica de la obtención de beneficios en función de la contribución a la verdad, la paz y la reparación, con base en sus aportes a la Comisión de la Verdad o a la Unidad de Búsqueda de Personas Desaparecidas que podrían ser valorados como un insumo relevante a la hora de determinar el tipo de beneficios a los que puedan acceder estos sujetos, según lo establezca la ley (Corte Constitucional, 2017).

Conforme a estos presupuestos, la corte declara la inexequibilidad de la norma que establece la competencia la JEP para investigar, juzgar y sancionar a los no combatientes en el conflicto armado, esto es, de los terceros civiles, es decir, los incisos $2^{\circ}$ y $3^{\circ}$ del artículo transitorio 16 del artículo $1^{\circ}$ del Acto Legislativo 01 de 2017. Dadas estas circunstancias, surge la pregunta 
¿Es conveniente o inconveniente que la JEP no tenga competencia obligatoria sobre terceros vinculados al conflicto armado?

\section{SOBRE LA INEXEQUIBILIDAD DE LA COMPETENCIA OBLIGATORIA DE LA JEP RESPECTO A TERCEROS}

En primer lugar, cabe destacar que entre los actores constantes en el conflicto armado en Colombia, han participado además de los grupos guerrilleros, los paramilitares, agentes del Estado y empresas. Tal es el caso, del secuestro de Martha Nieves Ochoa, cercana a la mafia del cartel de Medellín, que tiene como respuesta la creación del Movimiento Muerte a Secuestradores (MAS.), donde confluyeron narcotraficantes, militares en retiro y en servicio activo, policías, empresarios y ganaderos (Chaparro, 2013).

Estos terceros vinculados al conflicto tienen un papel determinante en la búsqueda de la verdad, pues como actores directos e indirectos, han tenido participación y permanencia en sus actuaciones relacionadas con la violación de derechos humanos. La posibilidad de hacerlos comparecer de manera obligatoria para que contribuyan a los elementos de la justicia transicional, posibilitaría una verdadera apuesta estructural de construcción y consolidación de una paz estable. Si se revisa el Informe General Basta Ya, cuando se recogen las experiencias de Justicia y Paz, se identifica un resultado interesante plasmado de la siguiente manera:

Es a través de las voces de los victimarios que algunos jueces y en parte la sociedad, están reconociendo la brutalidad de la guerra que las víctimas han padecido. En algunos informes, el GMH recogió y documentó estos testimonios porque permiten confirmar las verdades narrativas de las víctimas y las complicidades y alianzas entre ejércitos ilegales y legales, entre actores armados, políticos y empresarios. En muchas ocasiones fue a través de estas versiones que se pudo lograr el reconocimiento público de centenares de crímenes (Grupo de Memoria Històrica, 2010, p. 22).

Esta reflexión indica que han existido terceros no combatientes que han tenido un grado de responsabilidad en las consecuencias del conflicto, dejando consigo víctimas que continúan en búsqueda de ser legitimadas y reconocidas. Articulando esa realidad con la historia del conflicto en Colombia, y de sus antecedentes con el periodo de la Violencia, el Capítulo III "La Violencia 1946-1965", del libro "Pasado y presente de la violencia en Colombia" (Braun, 2000), deja entrever cómo el poder económico fue el trasfondo de los conflictos, haciendo de la violencia un medio para preservar el funcionamiento de las empresas.

Para efectos de la justicia transicional, el hecho de involucrar a todos los actores del conflicto, permite tener una mirada integral de su ejecución hacia las víctimas. Según el Centro de Estudios Latinoamericanos de la Universidad de Oxford-CELUO-, en todo el mundo, la participación directa e indirecta de los terceros civiles, incluyendo los actores empresariales, ha sido incorporada a los escenarios de justicia transicional, tanto por las comisiones de la verdad como por las instancias judiciales especializadas, teniendo en cuenta que se trata de actores claves en los fenómenos de violencia generada por conflictos armados internos y por procesos dictatoriales.

Por lo tanto, retomando el debate en Colombia sobre la comparecencia o no de terceros vinculados al conflicto, y aduciendo a la intervención del CELUO, la corte debió acoger una noción amplia de responsabilidad empresarial, para que se pueda imputar responsabilidad tanto por 
su participación directa como indirecta en el conflicto armado en Colombia, y debe aclarar que las comisiones de la verdad tienen dentro de su mandato el deber de esclarecer el rol de estos actores, y que los mismos deben acudir a la JEP; o en su defecto a las instancias judiciales ordinarias (Corte Constitucional, 2017). Es así como a partir de la evaluación de modalidades de colaboración entre los actores combatientes y terceros, por ejemplo, la financiación de grupos que dieron como resultado realización de delitos cometidos en el marco del conflicto, deberían ser competencia obligatoria de la JEP respondiendo al deber de los Estados de investigar, juzgar y sancionar graves violaciones a los derechos humanos.

Cabe destacar que la justicia transicional tiene un importante uso democrático que ha sido realizado por distintos tribunales, entre ellos la Corte Interamericana de Derechos Humanos, quien ha jugado un rol activo en la elucidación de la verdad sobre el paramilitarismo en general, y sobre la colusión de sus miembros con agentes estatales en particular respecto al contexto colombiano. En palabras de Uprimny y Saffon, el esclarecimiento de la verdad de tales fenómenos resulta esencial para materializar no solo los derechos a la verdad, la justicia y la reparación de las víctimas que se han dirigido a la corte, sino también para satisfacer el derecho colectivo de la sociedad colombiana como un todo a conocer la verdad de las atrocidades pasadas. De esta manera, la Corte Interamericana de Derechos Humanos ha logrado establecer una doctrina según la cual el Estado puede ser declarado responsable internacionalmente por acciones de terceros. Es así como la corte ha logrado condenar al Estado colombiano a pagar reparaciones a las víctimas de masacres cometidas por grupos paramilitares (Uprimny-Saffon, 2008).

El anterior enunciado que si bien, data de años anteriores a todo el proceso de implementación del acuerdo final, permite advertir un elemento fundamental de la justicia transicional que corresponde a la verdad. En esa medida, si bien a nivel interno se ha definido restringir la competencia de la JEP sobre terceros, aun cuando estos podrían contribuir determinantemente a la verdad, queda en prospectiva la posibilidad de acudir a instancias alternas internacionales para agotar los propósitos democráticos de la justicia transicional.

En suma, para el contexto colombiano sería realmente conveniente la competencia de la JEP sobre terceros, en tanto se tornaría factible tener la óptica de la verdad desde múltiples aristas. En todo caso, pese a los argumentos presentados por la Corte Constitucional para justificar su improcedencia, esta negativa debe verse como una oportunidad, donde se trazan unos retos interesantes por construir en términos de estrategia jurídica y pedagógica sobre la implementación del acuerdo y sobre la defensa de las víctimas que siguen en el medio de la contienda política que plantea en este momento, tensiones alusivas a objetar o no la JEP. Son muchos los escenarios de construcción en los que se sigue gestando trabajo para la defensa de los derechos humanos.

\section{Conclusiones}

La Corte Constitucional ha fijado parámetros importantes para la comprensión del Estatuto de Roma como un componente del bloque de constitucionalidad; por lo tanto, la misma evolución jurisprudencial anterior y posterior a la ratificación de este instrumento, se ha concebido como la respuesta clara y dinámica a la armonización del ordenamiento interno con las disposiciones 
internacionales que versan sobre derechos humanos. En ese sentido, cabe destacar que solo unas disposiciones específicas del Estatuto de Roma forman parte del bloque de constitucionalidad, dando lugar a la relevancia del principio de complementariedad que se fija para la competencia de la Corte Penal Internacional.

La postulación de la sentencia C-290 de 2002, resulta un referente importante para resolver una de las inquietudes más reiteradas relacionadas con la posible impunidad en el juzgamiento de máximos responsables de crímenes de guerra o lesa humanidad en relación con el funcionamiento de la Jurisdicción Especial para la Paz. De este modo, a la luz de la sentencia se concluye que bajo el mismo principio de complementariedad, de no funcionar las medidas adoptadas por la JEP para sancionar a los máximos responsables, sería factible la activación de la competencia de la Corte Penal Internacional, funcionando como un marco normativo que se extiende ante la eventualidad de la impunidad.

En ese orden de ideas, la existencia de la JEP, su funcionamiento y la constante observación de distintos organismos internacionales y sujetos de la comunidad internacional, ofrecen en el panorama actual, un sistema más robusto de garantías para la protección y reparación de las víctimas, que requiere en todo caso, contar con mayor agencia del Estado para aproximarse en mejor medida a los efectos esperados. Pese a las preocupaciones manifestadas por varios actores de la comunidad internacional respecto a la responsabilidad del mando y la aplicación del derecho internacional, en términos normativos se aprecia un desarrollo importante sobre los factores de macrocriminalidad relacionados con el juzgamiento de máximos responsables, que de no ser efectivos permiten la extensión de la competencia a la Corte Penal Internacional.

Finalmente, se aduce que la creciente dinámica del fenómeno sobre asesinatos de líderes sociales en el país, que no se encuadra en el espacio temporal dispuesto en la competencia de la JEP, trae consigo retos importantes sobre la integralidad de la comprensión y protección de los derechos humanos en todas sus escalas, dando como resultado, un rol importante del Estado en la construcción de políticas integrales que confronten la violencia sociopolítica y que permitan ponderar la necesidad de intervención de tribunales internacionales, que como órganos dispuestos para la conservación de la dignidad humana, cumplen un papel preponderante en la materialización de las medidas de reparación hacia las víctimas.

\section{Referencias bibliográficas}

Acto Legislativo 01, 01 (Congreso de La Repùblica 04 de 04 de 2017).

Alto Comisionado para la Paz. (24 de 11 de 2016). Acuerdo final para la terminación del conflicto y la construcción de una paz estable y duradera.Recuperado de: http://www. altocomisionadoparalapaz.gov.co/procesos-y-conversaciones/Documentos\%20compartidos/24-11-2016NuevoAcuerdoFinal.pdf.

Ambos, K (2010). Selección y priorización como estrategia de persecución en los casos de crímenes internacionales. Bogotá: Embajada de la República Federal de Alemania. 
Bensouda, F. (18 de 10 de 2017). epimg.ne. Recuperado el 16 de 03 de 2018, de http:// cr00.epimg.net/descargables/2017/10/21/17135b6061c7a5066ea86fe7e37ce26a. pdf?int=masinfo

Chaparro, N. (2013). Amnistia e Indulto 1965-2012. Bogotà: Universidad Nacional de Colombia.

Charry, J. (24 de 10 de 2017). Semana. Recuperado el 14 de 03 de 2018, de http://www.semana. com/opinion/articulo/estatuto-de-roma-y-jurisdiccion-especial-de-paz/544689.

Contreras, L. (05 de 05 de 2017). Cinep. Obtenido de http://www.cinep.org.co/Home2/ component/k2/item/416-dialogos-cinep-ppp-justicia-en-los-casos-de-lideres-sociales-asesinados.html.

Colombia. Corte Constitucional. Sentencia del 14 de Noviembre de 2017. Magistrado Ponente Luis Guillermo Guerrero Pérez. (Sentencia Número C-674). Recuperado de: http://www. corteconstitucional.gov.co/relatoria/2017/C-674-17.htm

Colombia, Corte Constitucional. Sentencia del 13 de Noviembre de 2001. Magistrado Ponente Eduardo Montealegre Lynett. (Sentencia SU-1184). Recuperado: http://www. corteconstitucional.gov.co/relatoria/2001/SU1184-01.htm

Colombia. Corte Constitucional. Sentencia del 12 de Marzo de 2002. Magistrado Ponente Jaime Cordoba Triviño. (Sentencia C-181). Recuperado: http://www.corteconstitucional.gov.co/ relatoria/2002/C-181-02.htm

Corte Penal Internacional, CPI. (01 de 07 de 2002). Recuperado el 15 de 03 de 2018, de un.org: http://www.un.org/spanish/law/icc/statute/spanish/rome_statute\%28s\%29.pdf

Dejusticia. (2017). Comentarios sobre el Proyecto de Ley Estatutaria de Administración de la Jurisdicción Especial para la Paz (JEP). Bogota: FIP.

Fundación Ideas para la Paz, FIP. Universidad del Rosario. Comisión Colombiana de Juristas. (27 de 10 de 2017). dejusticia.org. Recuperado el 15 de 03 de 2018, de https://www. dejusticia.org/wp-content/uploads/2017/10/27-10-2017-Comunicado-PLE-JEP-_final. pdf

Franco, Á. (2017). Confrontaciòn entre las disposiciones de las Jurisdicciòn Especial para la Paz y las oblñigaciones del Estado con la ratificaciòn del Estatuto de Roma. Bogota: Universidad Catòlica de Colombia.

Grupo de Memoria Histórica. (2010). ¡Basta Ya! Colombia: Memorias de Guerra y Dignidad. Bogotà: Comisiòn Nacional de Reparaciòn y Reconciliación.

Osorio, M. (2 de 12 de 2017). El Espectador. Obtenido de https://colombia2020.elespectador. com/territorio/lideres-sociales-los-silenciados-y-los-que-resisten.

Registro Nacional de Información. RNI. Unidad para las Víctimas. (05 de 06 de 2019). Unidadx 
de Victimas. Recuperado de: https://cifras.unidadvictimas.gov.co/.

Sentencia C-290, expediente D- 8776 (Corte Constitucional 18 de 04 de 2012).

Tiempo, E. (20 de 10 de 2014). Recuperado el 24 de 03 de 2018, de http://www.eltiempo.com/ archivo/documento/CMS-14717255.

Uprimny-Saffon, R.-M. (2008). Usos y abusos de la Justicia Transicional en Colombia. Anuario de Derechos Humanos, 165-195.

Vivanco, J. (14 de 11 de 2017). kienyke.com. Recuperado de: https://www.kienyke.com/politica/ human-rights-wash-con-la-lupa-en-la-jep. 